\title{
Short Communication: Morphometric variations in two populations of Limnophora marginata Stein, 1904 (Diptera, Muscidae) in Ecuador
}

\author{
MARÍA ALEJANDRA RUIZ, CAMILA ACOSTA-LÓPEZ, ANA SOTO-VIVAS ${ }^{\star}$ \\ Carrera de Ciencias Biológicas y Ambientales. Facultad de Ciencias Biológicas. Universidad Central del Ecuador. Campus El Dorado-Itchimbía. Numa \\ Pompilio Llona y Yaguachi EC170136. Quito, Pichincha 170403, Ecuador. Tel. + 593-22986259.`email: aysoto@uce.edu.ec
}

Manuscript received: 21 August 2020. Revision accepted: 19 April 2021.

\begin{abstract}
Ruiz MA, Acosta-López C, Soto-Vivas A. 2021. Short Communication: Morphometric variations in two populations of Limnophora marginata Stein, 1904 (Diptera, Muscidae) in Ecuador. Biodiversitas 22: 2654-2657. Limnophora includes 230 species, eleven of which are present in Ecuador. There are few studies on the bioecology of these species in the country. However, recent studies indicate that Limnophora marginata Stein, 1904 as the most abundant species in the Evergreen High Montane Forest (EHMF) located at 3400 masl in Tocachi parish, in contrast to a low abundance in the Dry Forest (DF) at 2500 masl in Malchingui parish, Pedro Moncayo Canton. This study was described the wing morphogeometric variation of L. marginata associated with these two habitats. Thirty-two wings were photographed: 16 specimens in EHMF and 16 in DF. The coordinates configurations $(x, y)$ were registered and aligned through Generalized Procrustes Analysis. The centroid size between habitats was significantly different (Kruskal-Wallis; $\mathrm{p}<0.005)$; EHMF specimens were larger than DF. Reclassification a posteriori was perfect in DF specimens (100\%), and almost perfect in EHMF (93.75\%). The landmarks that most contributed to the variation between habitats were: Interception between $\mathrm{M}$ and wing border, interception $\mathrm{dm}-\mathrm{cu}$, and interception between $\mathrm{Cu}$ and $\mathrm{dm}-\mathrm{cu}$. The wing morphometric variations observed in L. marginata could be associated with phenotypic plasticity.
\end{abstract}

Keywords: Bergmann's rule, geometric morphometrics, Limnophora, phenotypic variation

\section{INTRODUCTION}

Muscidae is one of the families of Order Diptera with higher diversity; including eight subfamilies: Achanthipterinae, Atherigoninae, Muscinae, Azeliinae, Phaoniinae, Mydaeinae, Coenosiinae, and Cyrtoneurininae; in Ecuador, 77 species are reported. The members of the family occupy tropical and high mountains as habitats. The species of the group have different habits and provide ecosystemic services as organic matter decomposers (Loewenberg-Neto and Carvalho 2013; Courtney et al. 2017).

In the Neotropical region, Coenosiinae is the most diverse subfamily, this group is characterized by aquatic larvae. The subfamily included Limnophoriini and Coenosiini, with cosmopolitan distributions. Most species of Limnophoriini, associated with humid environments such as flooded soils and moss, whilst some grow in dry environments. To this date, 12 genera are reported for the neotropics (Loewenberg-Neto and Carvalho 2013).

The Limnophora genus is formed by 230 species, known for using different habitats. They are found from high mountains to valleys, rivers, and streams; inhabiting both high forests and dry forests (Xue et al. 2012). In Ecuador had been reported: Limnophora bifasciata Fogaca and Carvalho 2015, L. longivittata Fogaca and Carvalho 2015, L. polleti Fogaca and Carvalho 2015, L. equatoriensis Fogaca and Carvalho 2015, L. femurosetalis Fogaca and Carvalho 2015, L. lamasi Fogaca and Carvalho 2015, L. penai Fogaca and Carvalho 2015, L. marginata Stein 1904,
L. pica (Macquart, 1851) and L. saeva (Wiedemann, 1830) (Loewenberg-Neto and Carvalho 2013; Fogaça and Carvalho 2015).

The ecology and biology of the Limnophora species are limited. Recently, Moreira (2019) studied the diversity and composition of Muscidae in two altitudinal gradients in Pedro Moncayo Canton, Pichincha - Ecuador; found $L$. marginata as the most abundant species associated with the Evergreen High Montane Forest (EHMF), in contrast to a lower abundance in Dry Forest (DF). Later, Blacio et al. (2020) investigated the diversity and synanthropy in sarcosaprofagous Diptera was associated with EHMF; they found a higher positive synanthropic index for $L$. marginata. Species such as this one, give good candidates for analyzing the influence of environmental conditions in phenotypic variation.

The variation of the shape of the wing in Diptera, comes forward as a good morphological marker to study variations in populations. Studies such as the one presented by Alves et al. (2016) refer that some dipteran species exhibit variations in morphological traits correlated with selective pressures such as temperature. In the same way, the effects of the altitude in morphological characters in Diptera have been reported. In this sense, as a contribution to the knowledge of Diptera in Ecuador, this study describes the morphogeometric variations of the wings in two populations of $L$. marginata. The CIFV3-CV-FCB3 Project/Research Direction and Faculty of Biological Sciences. Project developed with research permit No. 007- 
2018-RIC-FLO-FAU-DPAP-MA and collection permit No. 007-2019 -DPAP-MA.

\section{MATERIALS AND METHODS}

\section{Biological samples and collection site}

The $L$. marginata specimens were collected between May 2017 and November 2018, in the Tocachi parish, in EHMF (-78.290500 Longitude W 0.048400 Latitude N) and the Malchingui parish, in DF (-78.358324 Longitude W, -0.000693 Latitude S); located at Pedro Moncayo Canton of the Pichincha Province, Ecuador Ecuador (Cuesta et al. 2017; Moreira 2019).

The EHMF appertains the High Montane Forest classification, it extends from an altitude of 3000 to 3400 masl, and it displays tempered cold weather with a temperature between 6 and $14{ }^{\circ} \mathrm{C}$ with annual precipitation of $922 \mathrm{~mm}$. The forest exhibits vegetation of a transition zone between Paramo and Montane Forests of zones with a higher altitude, with trees having ramifications starting from the base of the moss coating). The wildlife of the forest includes well-adapted species with specific feeding habits, while the flora features trees with a canopy of 15 to $20 \mathrm{~m}$ with epiphytes. The DF appertains Espinar's Montane Dry Forest and Montane Dry Shrub classifications, it is located between 1400 and 2500 masl, exhibits annual mean precipitation that varies between the 200 to $575 \mathrm{~mm}$, its temperature ranges between 5 and $18{ }^{\circ} \mathrm{C}$. The species of flora and wildlife in this forest are perfectly adapted to drought, its forests exhibit bushes up to $2 \mathrm{~m}$ high and are present in the montane slopes of dry streams in Ecuador (Cuesta et al. 2017; Moreira 2019).

\section{Data acquisition}

This study was following the criteria of Cardini et al. (2015) and De Luna (2020) who indicate that geometric morphometry is an informative tool for the detection of anatomical variations. Where the total size of the sample must be greater than the variables analyzed to obtain a reliable estimate of the variance-covariance structure in the data. These authors mentioned that the size of the centroid is very precise; even when the sample size is small and the number of samples required to achieve a reasonable degree of precision may be between 15-20 samples. In this sense, after identifying the biological material, a total of 32 wings of female specimens were dissected and slide mounting: 16 collected in the EHMF, and 16 DF. In each wing, eight landmarks (LM 1-8) were located, corresponding with the type I sensu: LM 1, rupture of the subcosta; LM 2, a junction of R1 with the border of the wing; LM 3, a junction of R2+3 with the border of the wing; LM 4, a junction of R4+5 with the border of the wing; LM 5, a junction of $\mathrm{M}$ with the border of the wing; LM 6, a junction dm-cu; LM 7, junction of $\mathrm{Cu}$ with dm-cu and LM 8, a junction of $\mathrm{M}$ with $\mathrm{r}-\mathrm{m}$. The configuration of the eight pairs of coordinates $(x, y)$ of each wing (Figure 1) was captured with the help of the TPSDig program (De Luna 2020).

\section{Geometric morphometrics analysis}

From the matrix of the 32 configurations of geometrical coordinates of the eight landmarks (LM1-8), the Generalized Procrustes Analysis was conducted, with the CoordGen software (Sheets 2005a) to obtain a matrix with the conformational variables (partial warps $=\mathrm{Pw}$ ) and the centroid size (CS). This Pw matrix was used to perform a principal component analysis and analysis of Canonical Variables with the PCAGen and CVAGen software, through which the proportion of reclassified groups (EHMF and DF) was found, and a MANOVA analysis was performed for each canonical axis (De Luna 2020). The difference in CS values between habitats was analyzed with a Kruskal-Wallis test (P 0.05). Finally, we calculate the relative deformations compared to the average shape of the studied populations (relative deformations or $\mathrm{Rw}$ ) (Klingenberg 2013).

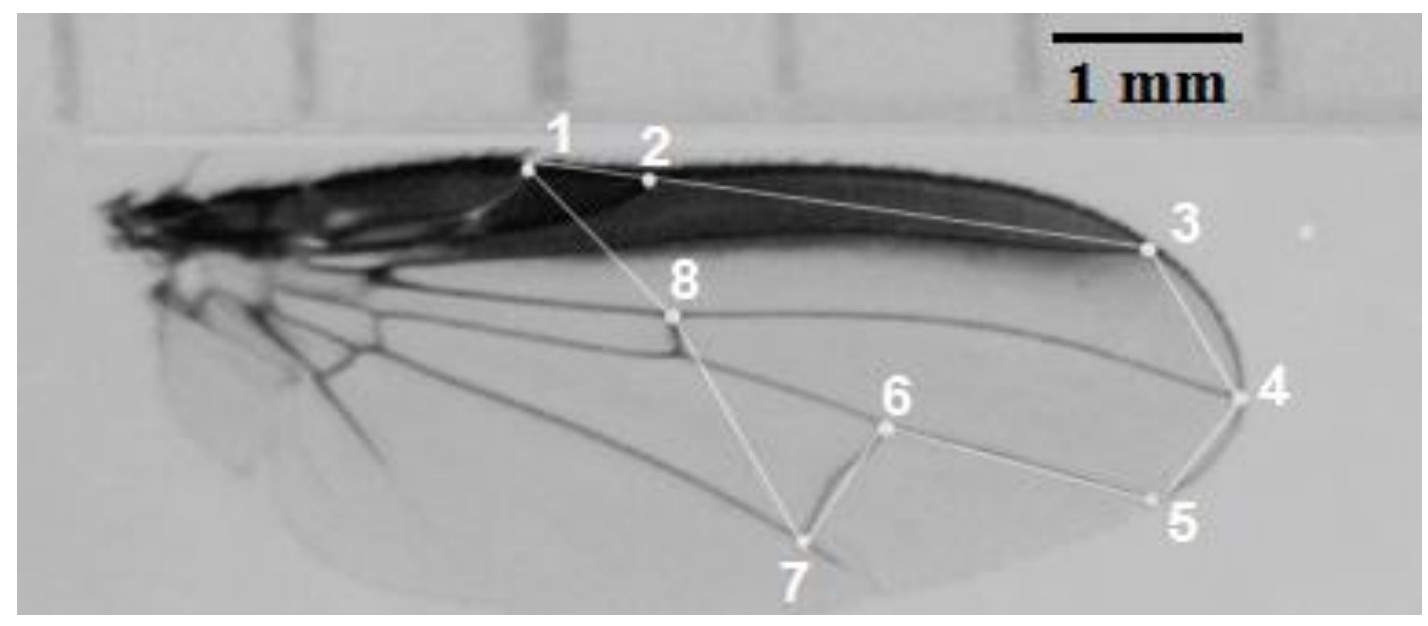

Figure 1. Photograph of the right-wing of L. marginata, showing the disposition of the anatomical reference landmarks (LM). LM 1, rupture of the subcosta; LM 2, a junction of R1 with the border of the wing; LM 3, a junction of R2+3 with the border of the wing; LM 4, a junction of R4+5 with the border of the wing; LM 5, a junction of M with the border of the wing; LM 6, a junction dm-cu; LM 7, a junction of $\mathrm{Cu}$ with dm-cu and LM 8, a junction of $\mathrm{M}$ with $\mathrm{r}-\mathrm{m}$. 


\section{RESULTS AND DISCUSSION}

Statistically, significant difference was found in the centroid size of L. marginata between habitats (KruskalWallis $X 2=8.42 ; p<0.0037$ ); the specimens from EHMF were larger $(2.004 \mathrm{~mm} \pm 0.171)$, in comparison with the ones from the DF $(1.805 \mathrm{~mm} \pm 0.134)$.

Principal component analysis (PCA) indicates that PCA1 and PCA2 explain $42 \%$ and $22 \%$ of the sample variance, respectively. The anatomical points that improve the total variance in the sample are PAR 2, 6, and 7. The PCA of $L$. marginata for each forest is observed in Figure 2.

The CVA shows a total variation of $66 \%$ (CVA1= $47 \%$, CVA2 $=19 \%$ ). The lambda Wilks values, X2, degrees of freedom, and probabilities in the reclassification test in the discriminant axe from the CVA were respectively: $\Lambda 1$ $=0.2718, \chi^{2}=31.26$, df $=12$, and $\mathrm{p}<0.001$. The percentage of reclassification a posteriori analyzed through CVA indicates $100 \%$ of reclassification (16/16) for $L$. marginata belonging to DF and $93.75 \%$ of correct reclassification $(15 / 16)$ for $L$. marginata collected in EHMF

The interpolation function of the thin plate spline, allowed to describe conformational differences as deformations of the eight analyzed landmarks. In the data plot of the intraspecific analysis of $L$. marginata amongst the two habitats, the crosses correspond to the $L$. marginata specimens from EHMF and the black dots to the DF specimens. The deformation grill A displays the wing changes that are present in L. marginata both in the EHMF and DF (Figure 2.A). Changes were determined in $L$. marginata, collected in the EHMF and the DF. The greatest deformations are observed at the junction of $\mathrm{R} 1$ with the edge of the wing (LM 2), it moves diagonally to the right towards R2 + 3 with the edge of the wing (LM 3); the dmcu junction and the $\mathrm{Cu}-\mathrm{dm}-\mathrm{cu}$ junction (LM 6 and LM 7 respectively) move diagonally to the left towards the lower edge of the wing and the M-rm junction (LM 8) moves anteriorly part of the wing, causing the cells of the warp grid to widen.

The shape and size variation detected in this study in $L$. marginata, may be due to phenotypic plasticity, in response to environmental conditions such as temperature and altitudinal gradient. This was confirmed by Alves et al. (2016), who mentions that in Muscidae, the environmental factors influence directly the shape and size variability of the wings. Specimens that showed the smaller size and thinner shape of the wing were registered in the DF, which inhabit between 1400 to 2500 masl, where temperature varies between 12 and $18{ }^{\circ} \mathrm{C}$. In the dry season, the temperature might be between 18 to $22{ }^{\circ} \mathrm{C}$ during the day and $-2^{\circ} \mathrm{C}$ at dawn (Moreira 2019). Whereas the specimens of L. marginata that showed the bigger size and wider wings, are distributed in the EHMF, inhabiting between 3000 and 3400 masl with an annual mean temperature that varies between 6 and $14^{\circ} \mathrm{C}$.

Carl Bergmann in 1847, proposed that individuals of a species or clade in higher latitudes, are bigger than those in lower latitudes (Shelomi 2012). Bergmann, indicates that thermal regulation would be the factor that explains the larger size in animals that inhabit higher altitudes, given that the relation surface/volume, allows reducing the heat loss in colder environments. Some insects like Diptera, thermoregulate their temperature, the bigger the body the slower the heat loss, enabling them to tolerate lower temperatures (Azócar et al. 2016).

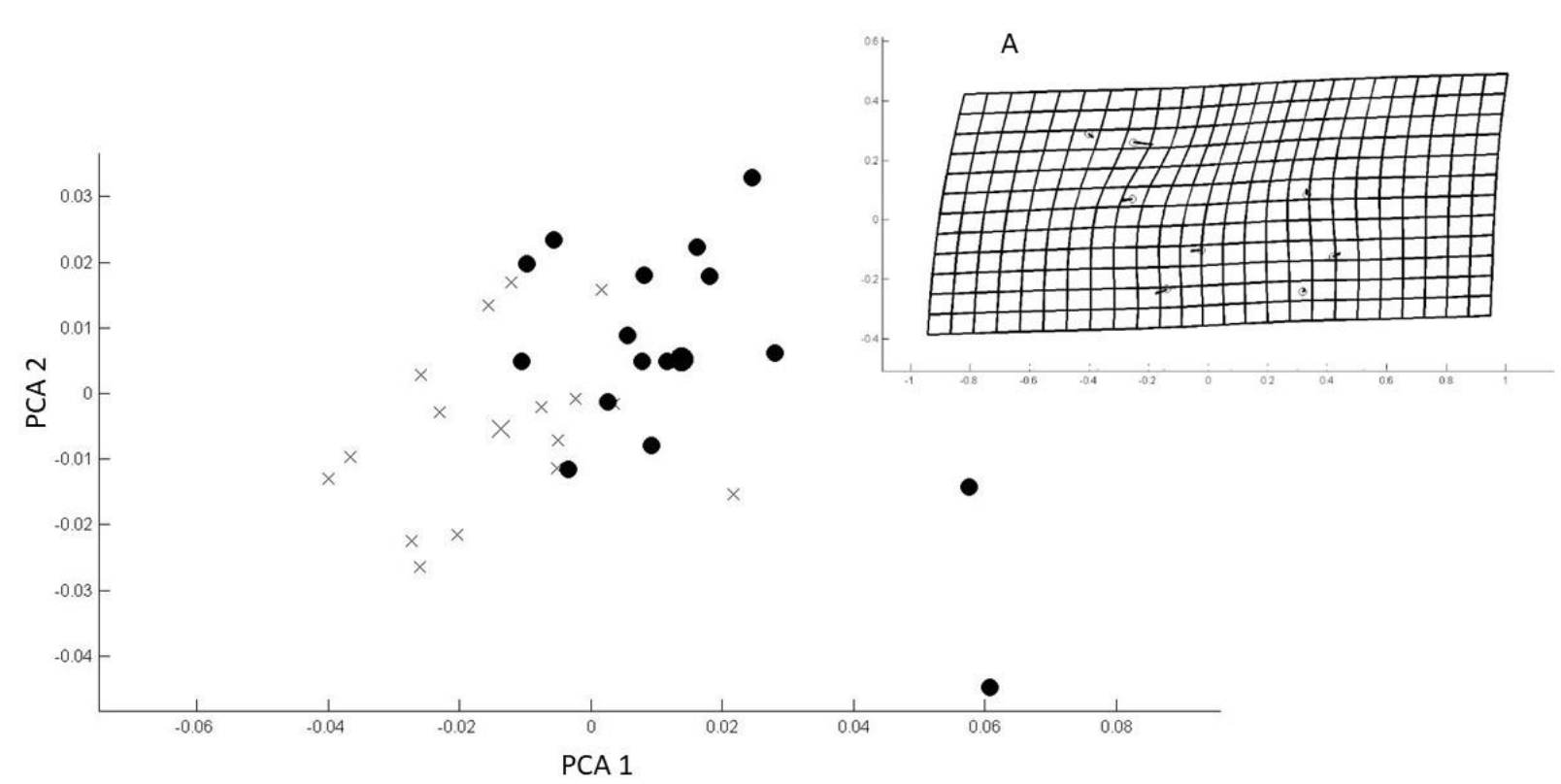

x L. maginata of Evergreen High Montane Forest

- L. maginata of Dry Forest

Figure 2. Diagram of the two first components principals PCA for the 32 specimens of L. marginata, showing the deformation grid in the conformations. A. Deformation grid, shows the changes between mean wing configuration of the two populations studied. 
However, little is known of the bio-ecology of $L$. marginata, recently Moreira (2019), mentions the species, as the most abundant in the EHMF and with higher synanthropic value in the Tocachi parish, Pedro Moncayo Canton (Blacio et al. 2020). Krivosheina et al. (2014), mentions that most of the Limnophora species, in their immature phase develop in aquatic environments, in streams with flowing water and rapid fluxes, some of them submerged in algae or moss. The same authors indicate that larvae and adults are predators, of other invertebrates. In this study larvae were not collected, for this reason, the natural breeders of the species are not known. Nevertheless, the variation in shape and size of the wing could be related to the availability of nourishment during the development of the larvae stage, causing intra and interspecific competition for food (Sasmita et al. 2019).

The metric changes are associated with the environmental pressures are the first changes that can be detected in populations. Changes in altitude consider indirectly some variables, amongst them temperature and rainfall, that affect the ecology of the species. Previous studies like the one reported by Demirci et al. (2012) and Gómez et al. (2014), have found phenotypic differences in populations of Culicidae located at different altitudes, both studies support the adaptative explication previously described, suggested by Bergmann. The results obtained in this work agree with the ones reported by Courtney et al. (2017), who indicate that Diptera found in high and cold environments are larger. Sasmita et al. (2019), compare in their study, diets and temperature, concluding that temperature is a factor that affects the size of individuals. However, the results of this study coincide with those obtained by Demirci et al. (2012) and Motoki et al. (2012), which suggests that there is a direct correlation between wing shape and size with the altitudinal gradient.

In conclusion, morphogeometric patterns detected in the wing in L. marginata, are related to the fact that phenotypic plasticity is adaptive, in this case, it could be regulated by the temperature and altitude that the studied populations occupy, with the habitat and possibly with the elevation. This is the first study that seeks to explain the morphogeometric variations in L. marginata. However, it is necessary to continue studies of the biology and distribution of the species in the country to corroborate whether the patterns observed in the populations studied are associated with the habitat.

\section{ACKNOWLEDGEMENTS}

This research was financed by the Biological Sciences Faculty/Research Direction - Universidad Central del Ecuador (Grant cif3-cv-fcb-3).

\section{REFERENCES}

Alves VM, Moura MO, Carvalho JB. 2016. Wing shape is influenced by environmental variability in Polietina (Stein) (Diptera: Muscidae). Rev Bras Entomol 60: 1-7. DOI: 10.1016/j.rbe.2016.02.003.

Azócar DL, Bonino MF, Perotti MG, Schulte JA, Abdala CS, Cruz FB. 2016. Effect of body mass and melanism on heat balance in Liolaemus lizards of thegoetschi clade. J Exp Biol 219 (8): 11621171. DOI: $10.1242 /$ jeb.129007.

Cardini A, Seetah K, Barker G. 2015. How many specimens do I need? Sampling error in geometric morphometrics: Testing the sensitivity of means and variances in simple randomized selection experiments. Zoomorphology 134: 149-163. DOI: 10.1007/s00435-015-0253-z.

Courtney GA, Pape T, Skevington JH, Sinclair BJ. 2017. Biodiversity of Diptera. In: Foottit RG, Adler PH (eds). Science and Society Vol. I, Second Edition. DOI: 10.1002/9781118945568.ch9.

Cuesta F, Peralvob M, Merino-Viteric A, Bustamanteb M, Baquerob F, Freileb J, Murielc P, Torres-Carvajalc O. 2017. Priority areas for biodiversity conservation in mainland Ecuador. Neotrop Biodivers 3 (1): 93-106. DOI: 10.1080/23766808.2017.1295705.

Blacio K, Liria J, Soto-Vivas A. 2020. Diversity and synanthropy of flies (Diptera: Calyptratae) from Ecuador, with new records for the country. J Threat Taxa 12: 15784-15793. DOI: 10.11609/jott.5479.12.8.15784-15793.

Demirci B, Lee Y, Lanzaro G, Alten B. 2012. Altitudinal genetic and morphometric variation among population of Culex theileri Theobald (Diptera: Culicidae) from Northeastern Turkey. J Vector Ecol 37 (1): 197-209. DOI: 10.1111/j.1948-7134.2012.00217.x.

De Luna E. 2020. Integrating morphometric and phylogenetic analyses: From phenetic systematics to phylogenetic morphometrics. Acta Bot Mex 127: e1640. DOI: 10.21829/abm127.2020.1640.

Fogaça J, Carvalho CJ. 2015. Seven new species of Limnophora Robineau-Desvoidy (Diptera: Muscidae) from Ecuador. Rev Bras Entomol 59 (3): 210-221. DOI: 10.1016/j.rbe.2015.05.001.

Gómez G, Márquez E, Gutiérrez L, Conn J, Correa M. 2014. Geometric morphometric analysis of Colombian Anopheles albimanus (Diptera: Culicidae) reveals significant effect of environmental factors on wing traits and presence of a metapopulation. Acta Trop 135: 75-85. DOI: 10.1016/j.actatropica. 2014.03.020.

Klingenberg C. 2013. Visualizations in geometric morphometrics: How to read and how to make graphs showing shape changes. Hystrix 24: 1524. DOI: 10.4404/hystrix-24.1-769.

Krivosheina N, Krivosheina M. Krivosheina N, Krivosheina M. 2014. To the biology of muscid flies of the genus Limnophora RobineauDesvoidy, 1830 (Diptera: Muscidae). Caucasian Entomol Bull 10(2): 297-304.

Loewenberg-Neto P, Carvalho CJ. 2013. Muscidae (Insecta: Diptera) of Latin America and the Caribbean: Geographic distribution and checklist by country. Zootaxa 3650 (1): 1-147. DOI: 10.11646/zootaxa.3650.1.1.

Moreira 2019. Diversidad y composición de Muscidae (Insecta: Diptera) en dos gradientes altitudinales del cantón Pedro Moncayo, PichinchaEcuador. Trabajo de grado. Universidad Central del Ecuador, Quito. [Spanish]

Motoki MT, Suesdek L, Bergo ES, Sallum MA. 2012. Wing geometry of Anopheles darlingi Root (Diptera: Culicidae) in five major Brazilian ecoregions. Infect Genet Evol 12 (6): 1246-52. DOI: 10.1016/j.meegid.2012.04.002.

Sasmita H, WuChun T, LeeJin B, KokBoon N. 2019. Effects of larval diets and temperature regimes on life-history traits, energy reserves and temperature tolerance of male Aedes aegypti (Diptera: Culicidae): optimizing rearing techniques for the sterile insect programmes. Parasites Vectors 12 (1): 578-593. DOI: 10.1186/s13071-019-3830-z.

Shelomi M. 2012. Where are we now? Bergmann's rule sensu lato in insects. Am Nat 180 (4): 511-519. DOI: 10.1086/667595.

Xue WQ, Bai SC, Dong WX. 2012. A study of the genus Limnophora Robineau-Desvoidy (Diptera: Muscidae), with descriptions of six new species from China. Insect Sci 12 (17): 1-20. DOI: 10.1673/031.012.1701. 